\title{
Measuring Epistemic Weather Curiosity: Initial Development and Validation of an Individual Difference Questionnaire
}

\author{
Matthew J. Bolton, ${ }^{1,2}$ Lara K. Ault, ${ }^{1}$ Keith Burton, ${ }^{1}$ \\ Dylan R. Allen ${ }^{2}$ and H. Michael Mogil ${ }^{2}$ \\ ${ }^{1}$ College of Arts and Sciences, Saint Leo University, Saint Leo, FL \\ ${ }^{2}$ How The Weatherworks, Naples, FL
}

This version, $1 / 28 / 2022$, corrects a hypothesis-data wording inconsistency with respect to negative affect and curiosity.

Correspondence concerning this article should addressed to Matthew Bolton, College of Arts and Sciences, Saint Leo University, Saint Leo, FL. Email: $\underline{\text { Matthew.Bolton@email.saintleo.edu }}$

Preprinted 2021. 


\begin{abstract}
This paper addresses work at the intersection of meteorology and the psychology of curiosity and learning (Bolton et al. 2020; Stewart et al. 2015, 2018). Specifically, we report on the development and validation of the first self-report measure of epistemic (i.e., information-based) weather curiosity. Two studies derived 11 items measuring general interest in learning about weather and curiosity for the science behind weather. Psychometric properties and implications of the scale for use by meteorologists, educators, and academic researchers are discussed.
\end{abstract}




\section{Measuring Epistemic Weather Curiosity: Initial Development and Validation of an Individual Difference Questionnaire}

Weather, often considered to have strange and unusual properties (e.g., Ludlum, 1984; Seargent, 2012), has fascinated humankind for centuries. One needs only look to the myriad studies of its nature for evidence of this captivation (e.g., Bjerknes, 1921; De Figueiredo Neves et al., 2017; Jankovic, 2006; Howard, 1803; Helmholtz, 1858; Meleshko \& Aref, 2007). What are some psychological variables that might help explain weather curiosity?

First, we consider, in the personality domain, openness to experience. Openness sits alongside conscientiousness, extraversion, agreeableness, and neuroticism in the Five Factor Model of personality (Soto \& John, 2017). First used by Rogers (1954), the term reflects an individual's predisposition to embrace, in Soto and John's words (2017, p. 120), “a wide versus narrow range of perceptual, cognitive, and affective experiences." A crucial distinction is that it does not connote openness to social experience (this is extraversion; see, e.g., Sneed et al., 1998), but rather to more inner, cognitive events. Highly open people tend to be intellectually and aesthetically curious, with tendencies for deep thinking and to value artistic pursuits, and to have creative imaginations.

Weather salience theory (Stewart, 2009) provides another, more directed framework through which to understand this curiosity. As with other individual differences, weather salience-a quantification of the attention an individual directs towards weather-exists along a continuum so that one is more or less attuned to meteorological phenomena and may thus pay them increased or decreased attention. Weather salience is driven by cognitive appraisal of, and physical sensitivity to, the natural environment (Evans \& Cohen, 1987; Evans \& Stecker, 2004; Stewart, 
2009; Stokols, 1979, 1995). Such attunement may predict weather knowledge and information use (Stewart et al., 2012; Williams et al., 2017) and may be enhanced in particular clinical populations and individuals with particular cognitive styles (those with autism spectrum conditions; Bolton, Blumberg et al., 2020). Recent work suggests adult weather salience may stem in part from childhood weather-learning experiences (Bolton et al., 2020).

Cognitive style theories (Kozhevnikov, 2007) such as empathizing-systemizing (BaronCohen, 2020) might also help explain weather curiosity. Systemizing, formulated as the drive and ability to identify and generate psychological systems, or sets of logical rules used to explain the workings of the physical world, attempts to explain aspects of autism spectrum conditions (Baron-Cohen, 2020). We are interested in the detail-orientation aspects of systemizing and the manner in which it drives predictions of certainty. Ideal systemizing involves keeping variables constant and changing only one parameter at a time (Baron-Cohen, 2006; Bolton, Blumberg et al., 2020) so that each change can be observed relative to the overall system. This allows for the verification of predictability through an understanding of system sensitivity (Bolton, Blumberg et al., 2020; Tullett et al., 2015). It has been suggested (Bolton, Blumberg et al., 2020; Bolton et al., 2020) that systemizing-weather relations are linked to perceptions of chaos and weatherrandomness.

Another variable considered here is perceptual weather curiosity. Stewart created the Weather Curiosity Scale (2017) to measure a type of weather curiosity embodied in sensorydriven curiosity for sights (e.g., beauty appreciation); smells (e.g., of rain); tastes (e.g., of snow); sounds (e.g., wind rustling through trees), and textures (e.g., the supposed feeling of clouds) associated with weather. This relationship with weather entails trait sensitivity to environmental stimulation and the manner in which people experience emotions and manifest their 
personalities. Stewart (2017) found increased perceptual weather curiosity among those with more intense emotional experiences and in more socially-outgoing (i.e., extraverted) individuals.

Finally, epistemic curiosity (EC) is the naturally-occurring drive to seek new information (Litman \& Spielberger, 2003). There are two types, Interest (I-type) and Deprivation (D-type). Itype considers that individuals intrinsically enjoy discovering new things and want to learn more about them. D-type is experienced when individuals lack information and are driven to fill a knowledge deficit (Litman, 2008). Individuals may thus experience either positive feelings as a result of new learnings, or negative feelings due to lack of certainty about a topic (Litman \& Jimerson, 2004).

Yet, despite these learnings related to the ways in which people perceive, process, respond to, and use weather information and related environmental stimuli in the world around them, research has not yet explored the epistemic side of weather curiosity (EWC) related to a need for information about weather. This dearth of research has endured even as an information-based curiosity for the weather has clearly been manifest in the way weather phenomena have long enthralled people (Strauss \& Orlove, 2003; Maddern \& Jenner, 2009; Phan et al., 2018; Stewart, 2009; Stewart et al., 2012; U.K. Met Office, 2015). Recognizing that a validated measure of EWC could be useful to further study in this area and in, for example, K-12 learning physical science-learning environments (Stewart et al. 2015, Stewart et al., 2018), we designed a short questionnaire enabling its quantification. The study presented next reports our efforts to validate a new questionnaire of epistemic weather curiosity and to correlate it with a number of existing measures-of weather salience, systemizing cognitive style, openness to experience, epistemic curiosity and more specific perceptual weather curiosity, science curiosity, weather warning 
awareness, storm preparation self-efficacy (i.e., the belief one holds about being able to prepare for storms), and storm safety behaviors.

\section{Method}

\section{Participants and Procedure}

Participants were recruited internationally through social media for two online, Qualtricshosted surveys, with protocols approved by the Saint Leo University Institutional Review Board. Table 1, presented next, shows the participants' demographic composition. Open data, in SPSS and JASP format (for CFA), are available on the Open Science Framework website (https://osf.io/74n6w/). 
Table 1. Self-reported demographics for both studies.

\begin{tabular}{|c|c|c|c|c|c|c|c|c|}
\hline \multicolumn{9}{|c|}{ Study $1(\mathrm{~N}=209)$} \\
\hline \multicolumn{9}{|c|}{ Racial Classification } \\
\hline Caucasian & Hispanic & Asian & Latino/a & $\begin{array}{l}\text { Bi- or Multi- } \\
\text { racial }\end{array}$ & African American & \multicolumn{3}{|c|}{ Other } \\
\hline 172 & 10 & 8 & 8 & 4 & 1 & \multicolumn{3}{|c|}{6} \\
\hline \multicolumn{9}{|c|}{ Gender and Age } \\
\hline \multicolumn{3}{|c|}{$\begin{array}{c}\text { Women } \\
145\end{array}$} & \multicolumn{2}{|c|}{$\begin{array}{c}\text { Men } \\
61 \\
\end{array}$} & $\begin{array}{l}\text { Nonbinary } \\
3 \\
\end{array}$ & $\begin{array}{l}\text { Mean } \\
37.10\end{array}$ & $\begin{array}{c}\text { SD } \\
16.35 \\
\end{array}$ & $\begin{array}{l}\text { Range } \\
18-91\end{array}$ \\
\hline \multicolumn{9}{|c|}{ Weather Interest } \\
\hline \multicolumn{5}{|c|}{$\begin{array}{l}\text { Weather as Hobby or Interest }(\mathrm{n}=208) \\
\text { Yes }(93 ; 44.7 \%) \mid \operatorname{No}(115 ; 55.3 \%)\end{array}$} & \multicolumn{4}{|c|}{$\begin{array}{l}\text { Wanted to Be Meteorologist }(\mathrm{n}=93) \\
\text { Yes }(34 ; 36.6 \%) \mid \operatorname{No}(59 ; 63.4 \%)\end{array}$} \\
\hline \multicolumn{9}{|c|}{ International Distribution by Country } \\
\hline \multicolumn{9}{|c|}{ Study $2(\mathrm{~N}=236)$} \\
\hline \multicolumn{9}{|c|}{ Racial Classification } \\
\hline Caucasian & $\begin{array}{c}\text { African } \\
\text { American }\end{array}$ & Asian & Hispanic & Latino/a & Bi- or Multi-racial & \multicolumn{3}{|c|}{ Other } \\
\hline $201(85.1 \%)$ & 9 & 8 & 4 & 1 & 4 & \multicolumn{3}{|c|}{9} \\
\hline \multicolumn{9}{|c|}{ Gender and Age } \\
\hline & $\begin{array}{l}\text { Women } \\
5(78.4 \%)\end{array}$ & & 47 & $.9 \%)$ & $\begin{array}{l}\text { Nonbinary } \\
4(1.7 \%)\end{array}$ & $\begin{array}{l}\text { Mean } \\
41.14\end{array}$ & $\begin{array}{c}\mathrm{SD} \\
16.10 \\
\end{array}$ & $\begin{array}{l}\text { Range } \\
18-86 \\
\end{array}$ \\
\hline \multicolumn{9}{|c|}{ Weather Interest } \\
\hline \multicolumn{5}{|c|}{$\begin{array}{l}\text { Weather as Hobby or Interest }(\mathrm{n}=220) \\
\text { Yes }(102 ; 46.4 \%) \mid \operatorname{No}(118 ; 53.6 \%)\end{array}$} & \multicolumn{4}{|c|}{$\begin{array}{l}\text { Wanted to be Meteorologist }(\mathrm{n}=100) \\
\text { Yes }(33 ; 33 \%) \mid \operatorname{No}(67 ; 67 \%)\end{array}$} \\
\hline \multicolumn{9}{|c|}{ International Distribution by Country } \\
\hline United Sta & s: $206(87.3$ & & United Kingd & $: 11(4.7 \%)$ & Canada: $1(0.4 \%)$ & & her: 18 & $\%)$ \\
\hline
\end{tabular}


Across the two studies, participants responded to the demographic items shown in Table 1 and several individual difference, self-reported Likert-type measures related to the constructs discussed above (openness, weather salience, systemizing, perceptual weather curiosity, storm preparation self-efficacy beliefs and safety behaviors, and trait epistemic and science curiosities; note that they are presented next in the order to which participants responded to them). Cronbach's alpha $(\alpha)$, a standardized measure of item inter-correlation ranging from $0-1$, was calculated for all measures to assess internal reliability and suitability for use. For study 1 , these were the 7-item version of the Weather Salience Questionnaire (WxSQ; Stewart et al., 2012; $\alpha$ : 0.65); 10-item Systemizing Quotient (SQ; Greenberg et al., 2018; $\alpha$ : 0.74); 4-item Oklahoma Warning Awareness Scale (OKWAS; Allan et al., 2017; $\alpha$ : 0.92); 8-item Hurricane Personal Self-Efficacy Scale (HPSES; Stewart, 2015; $\alpha: 0.88$, and note that the items were modified to reference thunderstorms so we hereafter refer to the scale as the TPSES); and 15 items from the Storm Safety Behavior Scale (SSBS; Krause et al., 2017; $\alpha$ : 0.85).

Study 2 used 13 WxSQ items related to weather attention and sensing (Stewart, 2009; $\alpha$ : 0.81), the 10-item Interest and Deprivation (I-D) Curiosity Scale (Litman \& Spielberger, 2003; Interest $\alpha$ : 0.85, Deprivation $\alpha: 0.85$ ), 12-item Openness factor of the Big Five Inventory-2 (Soto \& John, 2017; $\alpha$ : 0.85); 12-item Science Curiosity in Learning Environments Scale (SCILE; Weible \& Zimmerman, 2016; $\alpha$ : 0.92), and 10-item SQ ( $\alpha: 0.83)$. Excepting the SCILE, used to assess discriminant validity, all remaining measures assessed convergent validity.

In an effort to begin improving weather salience and systemizing measurement, we (following the advice and psychometric recommendations of Wright \& Skagerberg, 2012) de- 
reversed the negatively-phrased items for the WxSQ and SQ questionnaires in Study 2. ${ }^{1}$ Save for the 7-item WxSQ in Study 1, all scales were reliable at typical alpha coefficient standards of 0.70. However, the original paper detailing its creation, and personal correspondence with Alan Stewart $(2019,2020)$, indicate low reliabilities tend to occur because of the manner in which it was constructed. It was not intended as a full measure of weather salience tendencies but rather as a very brief indicator of a broadly generalized psychological orientation towards weather.

Outlying questionnaire scores \pm 2.5 standard deviations (SD), except for the epistemic weather curiosity questionnaire (for which we aimed to examine score distributions), were removed.

\section{Questionnaire Construction}

Twenty-three items thought to be relevant to EWC measurement served as the basis for the scale. Consistent with the EC literature, items aligned with the notion that people are driven to understand how the weather works and are curious about weather information and correspondingly interested in acquiring it in a variety of ways.

Item formulations were influenced by the Children's Science Curiosity Scale (Harty \& Beall, 1984). We attempted to address that questionnaire's poor construct validity, due to its conceptualization of science curiosity as revolving solely around interest and not involving selfinitiated action towards obtaining scientific knowledge (Gardner, 1987), by creating items featuring active engagement in curiosity-driven, weather information-gathering activities. Participants were instructed to indicate agreement with each item (Table 2), on a 5-point, Likert-

\footnotetext{
${ }^{1}$ For example, on the WxSQ, "If a friend or family member asked me what the weather forecast was for today, I could not tell him or her what to expect" becomes "If a friend or family member asked me what the weather forecast was for today, I could tell him or her what to expect," and on the SQ, "When I hear the weather forecast, I am not very interested in the meteorological patterns" becomes "When I hear the weather forecast, I am very interested in the meteorological patterns."
} 
based scale from 1 (strongly disagree) to 5 (strongly agree). Summed responses yield a total score.

Table 2. Original items created to measure epistemic weather curiosity. Initial Item Pool

1. I would like to read magazines and/or stories about weather.

2. I like to watch television programs about weather.

3. I would like to listen to meteorologists talk about their jobs.

4. I want to know what causes wind.

5. I like to talk about the weather.

6. Movies and pictures about weather are interesting.

7. I like to watch TV news reports about weather.

8. I like to search for answers to questions about weather.

9. I feel drawn to learning about weather.

10. I have some interest in learning how to read computer weather models.

11. I would like to see the inside of a weather radar.

12. I want to know what causes tornadoes.

13. I am interested in learning about the tools meteorologists use to predict weather.

14. It would be interesting to see a weather balloon launch.

15. I like when meteorologists on TV talk about the science behind weather.

16. I would be interested in weather-related science experiments (e.g., creating a cloud in a bottle).

17. I am curious about why the weather changes.

18. TV news reports about weather are interesting.

19. I have some interest in learning how to read weather radar.

20. It is interesting to me that wildfires can sometimes create a type of tornado.

21. Weather easily captures my attention.

22. It would be interesting to tour and see inside a TV weather station.

23. I would like to learn about high and low pressure systems. 


\section{Data Analysis Plan}

An initial factor analysis was conducted on the EWC items in study 1 while confirmatory factor analysis was conducted in study 2 (CFA; Field 2013). After initial CFA, the items were further refined through systematic elimination based on the factor model uncovered in study $1 .^{2}$ Following these tests, correlational analyses were used to assess convergent validity. The determinant coefficient, Kaiser-Meyer-Olkin (KMO) Measure of Sampling Adequacy and Bartlett's Test of Sphericity determined whether the data were appropriate for exploratory analyses (Watkins, 2018).

Previous scholarship (Osborne, 2015; Tabachnick \& Fidell, 2014) recommends a 10:1 participant-item ratio. Our samples were $\mathrm{N}=209$ for study 1 and 235 for study 2; yielding 196 and 226 usable datapoints, respectively. These sample sizes were deemed sufficient given recruitment difficulties and the preliminary nature of the work.

Study 2 further tested the hypotheses that EWC would predict engagement with weather or weather information, and that weather-interested participants would be more anxious when induced to think about a situation in which they would be unable to engage in the curiositybased, information-gathering behaviors in our questionnaire. The regressions made use of five items ( $\alpha$ : 0.71; see Appendix A) generated to assess engagement with weather information, and eight negatively-valenced items from the Positive and Negative Affect Schedule (PANAS-SF; Watson et al., 1988; $\alpha$ : 0.90).

\footnotetext{
${ }^{2}$ CFA-supporting computations included the comparative fit (CFI), Tucker-Lewis (TLI), and goodness of fit (GFI) indices; standardized room mean residual (RMR); and the root-mean-square error of approximation (RMSEA).
} 


\section{Results}

\section{Study 1}

A principal components analysis set to load freely, and with oblique rotation, was deemed appropriate based on the determinant of $7.75 \times 10-8$, indicating a lack of multicollinearity; KMO score of 0.95; and Bartlett's $\chi^{2}$ of 3053.67 (df: 253), $p<0.001$. This analysis yielded a preliminary 3-factor structure (Table 3) with good communalities (i.e., no items inter-correlating either $<.2$ or $>.8)$.

Item themes clustered around active engagement in weather-learning (Factor 1, explaining $51.07 \%$ of the variance), curiosity for the science behind weather phenomena (Factor 2, explaining $7.53 \%$ of the variance), and multimedia-driven curiosity and engagement with weather (Factor 3, explaining $4.45 \%$ of the variance). However, 1 item loading $<.4$ was removed (Osborne, 2015), as were 3 cross-loading items (see Table 3 for items, including those removed which are denoted with asterisks). These were removed since the difference between crossloading items should be at least .2 in order for them to be retained (Kline, 1998). Repeating the factor analysis with the 4 items removed (also Table 3, see parentheses) merged the previous second and third factors, resulting in a general Curiosity about Weather Science factor. It also revealed two more cross-loading items, which were removed. 
Table 3. Results of the first two exploratory factor analyses.

Epistemic Weather Curiosity Questionnaire Items After First (and Second) EFA

Factor Loadings from Principal Components Analysis

\begin{tabular}{ll}
\hline \multicolumn{1}{c}{ Item } \\
\hline 1. I have some interest in \\
learning how to read \\
computer weather models.
\end{tabular}

2. I feel drawn to learning

$.655(.655)$ about weather.

3. I like to search for answers

$.646(.473)$ to questions about weather.

4. **I have some interest in Factor Loadings $>.4$ learning how to read weather radar.

5. I would like to see the inside .593 of a weather radar.

6. I would like to learn about .583 high and low pressure systems.

7. *I am interested in learning .539 about the tools meteorologists use to predict weather.

8. *I would like to read magazines and/or stories about weather.

9. **It would be interesting to $.405(.473) \quad(.430)$ $.646(.638)$ tour and see inside a TV weather station.

10. I would be interested in weather-related science experiments (e.g., creating a cloud in a bottle). 
11. It is interesting to me that

$.628(.599)$

wildfires can sometimes

create a type of tornado.

12. I am curious about why the weather changes.

13. I want to know what causes tornadoes.

14. I want to know what causes wind.

15. I like when meteorologists

on TV talk about the science behind weather.

16. It would be interesting to see a weather balloon launch.

17. *I would like to listen to meteorologists talk about their jobs.

18. I like to watch TV news reports about weather.

19. TV news reports about weather are interesting.

20. I like to watch television programs about weather.

21. Movies and pictures about weather are interesting. attention. weather.

\begin{tabular}{lc}
\hline Eigenvalues & $13.478(11.415)$ \\
\hline$\%$ of variance & $58.601(60.082)$ \\
\hline
\end{tabular}


The remaining items were subjected to a final analysis, which yielded 17 strongly reliable items across the two factors (Table 4; total $\alpha$ : 0.94; Factor 1: 0.90; Factor 2: 0.90) and accounted for $59.52 \%$ of the variance (Factor 1, 50.47\%; Factor 2, 9.06\%; see Table 4).

Table 4. Results of the third exploratory factor analysis.

Epistemic Weather Curiosity Questionnaire Items After Final EFA

Factor Loadings from Principal Components Analysis

\begin{tabular}{llcl}
\hline \multicolumn{1}{c}{ Item } & \multicolumn{2}{c}{ Factor Loadings Ordered Greatest-Least > } \\
& & & .4 \\
\hline & 1 & 2 & Communality \\
\hline 1. I would be interested in & .876 & & \\
$\begin{array}{l}\text { weather-related science } \\
\text { experiments (e.g., creating a } \\
\text { cloud in a bottle). }\end{array}$ & & & \\
\end{tabular}

2. It is interesting to me that $\quad .795$ wildfires can sometimes create a type of tornado.

3. I want to know what causes .771 wind.

4. I am curious about why the $\quad .747$ weather changes.

5. I want to know what causes $\quad .729$ tornadoes.

6. I would like to learn about $\quad .521$ high and low pressure systems.

7. I like when meteorologists $\quad .519$ on TV talk about the science behind weather.

8. I would like to see the inside $\quad .518$ of a weather radar.

9. It would be interesting to see .407 a weather balloon launch. 
10. I like to watch TV news

reports about weather.

11. TV news reports about

$-.870$

weather are interesting.

12. I like to watch television

$-.824$ programs about weather.

13. I feel drawn to learning $-.641$ about weather.

14. Weather easily captures my $-.628$ attention.

15. Movies and pictures about $-.617$ weather are interesting.

16. I have some interest in learning how to read computer weather models.

17. I like to search for answers to questions about weather.

\begin{tabular}{ll}
\hline Eigenvalues & 10.12 \\
\hline$\%$ of variance & 59.524
\end{tabular}




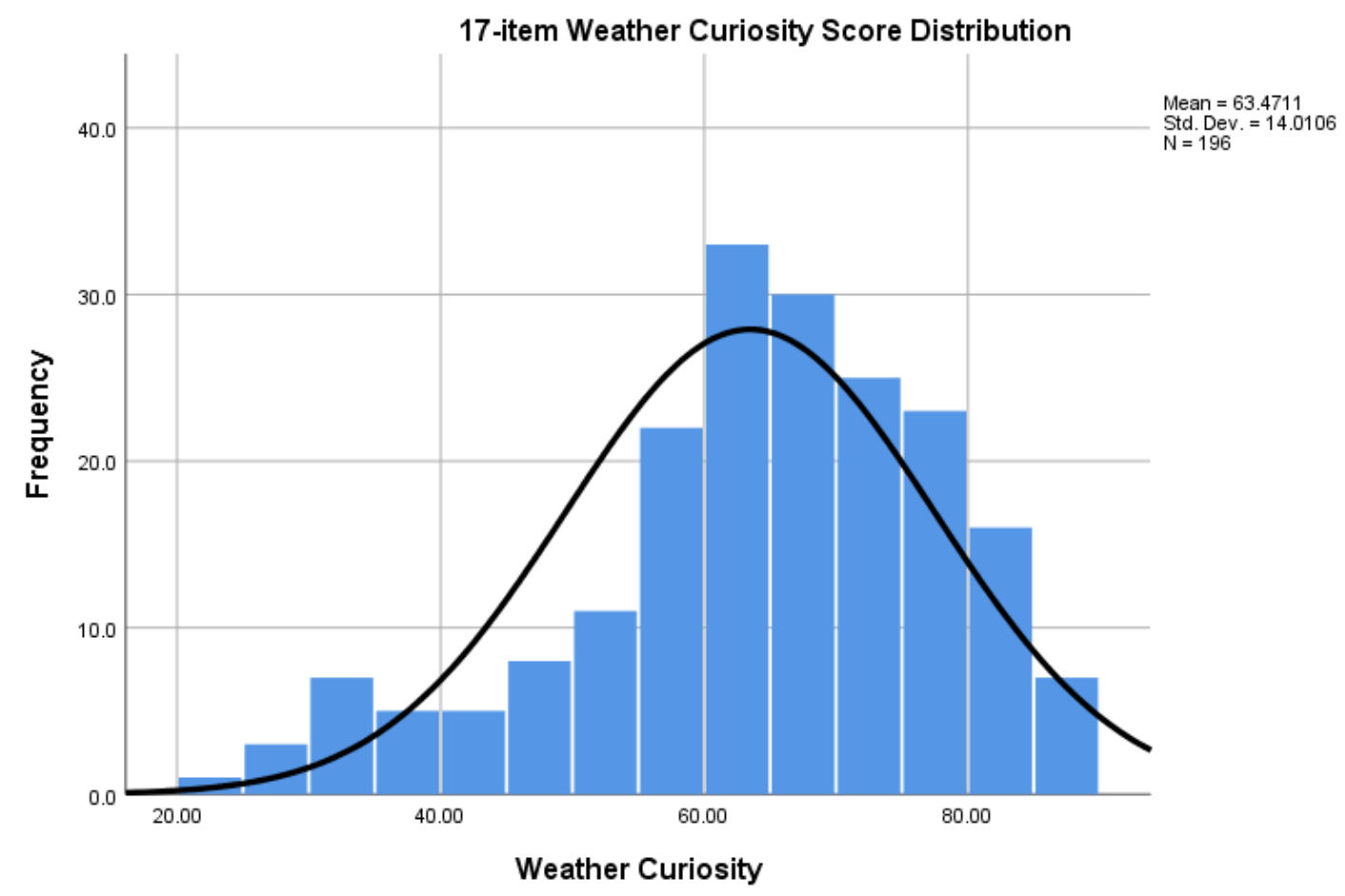

Figure 1. Distribution for the 2-factor, 17-item Epistemic Weather Curiosity Questionnaire derived through exploratory factor analyses in study 1 .

This left-skewed solution approximated a normal distribution (Figure 1) and was supported by one major inflexion point in the first analysis' scree plot (Figure 2; Kanyongo, 2005), lending credence to the two-factor structure as most parsimonious and interpretable. These items are henceforth referred to as the Epistemic Weather Curiosity Questionnaire (EWCQ). Pearson bivariate $r$ correlations showed good convergence with the accompanying measures (Table 5). 


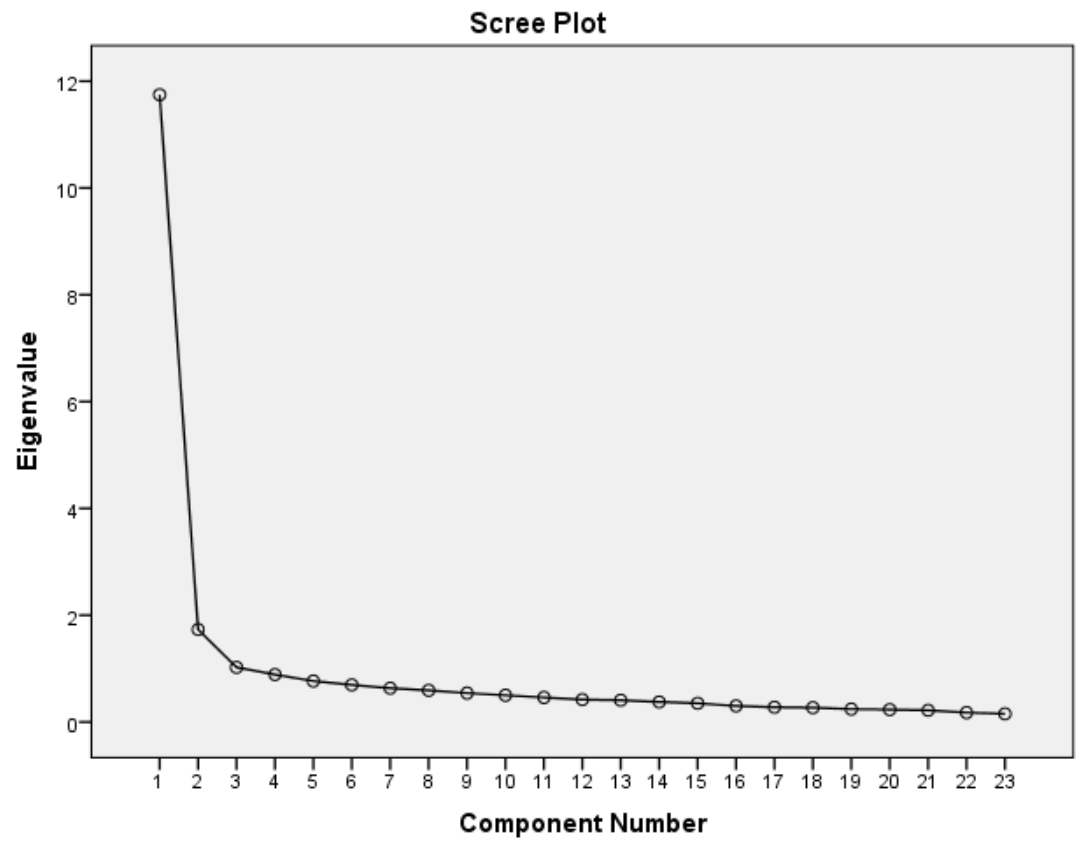

Figure 2. Scree plot from first exploratory factor analysis in study 1. 
Table 5. Pearson bivariate $r$ correlations for study 1.

\begin{tabular}{lllllll}
\hline Variable & WXSQ & SQ & OKWAS & TPSES & SSBS & EWxCQ-17
\end{tabular}

$\begin{array}{llll}\text { WxSQ } & n & - & \\ & \text { Pearson's } r & - & \\ & p \text {-value } & - & \\ & \text { Lower CI } & - & \\ \text { SQ } & n \text { Upper CI } & - & \\ & n & 196 & - \\ & \text { Pearson's } r & .51 & - \\ & p \text {-value } & <.001 & - \\ & \text { Lower CI } & 0.40 & - \\ & \text { Upper CI } & 0.61 & -\end{array}$

$\begin{array}{lllll}\text { OKWAS } & n & 188 & 184 & - \\ & \text { Pearson's } r & .38 & .385 & - \\ p \text {-value } & <.001 & <.001 & - \\ & \text { Lower CI } & 0.25 & 0.22 & - \\ & \text { Upper CI } & 0.50 & 0.47 & -\end{array}$

$\begin{array}{llllll}\text { TPSES } & n & 185 & 181 & 188 & - \\ & \text { Pearson's } r & .36 & .26 & .42 & - \\ p \text {-value } & <.001 & <.001 & <.001 & - \\ \text { Lower CI } & 0.22 & 0.12 & 0.30 & - \\ & \text { Upper CI } & 0.48 & 0.39 & 0.54 & -\end{array}$

$\begin{array}{lllllll}\text { SSBS } & n & 183 & 179 & 186 & 183 & - \\ & \text { Pearson's } r & .11 & .08 & .14 & .11 & - \\ & p \text {-value } & 0.149 & 0.292 & 0.063 & 0.133 & - \\ & \text { Lower CI } & -0.04 & -0.07 & -0.007 & -0.03 & - \\ & \text { Upper CI } & 0.25 & 0.22 & 0.28 & 0.25 & -\end{array}$

$\begin{array}{llllllll}\text { EWCQ-17 } & n & 193 & 188 & 190 & 187 & 185 & - \\ & \text { Pearson's } r & .53 & .52 & .44 & .36 & .10 & - \\ & p \text {-value } & <.001 & <.001 & <.001 & <.001 & 0.163 & - \\ & \text { Lower CI } & 0.42 & 0.40 & 0.32 & 0.23 & -0.04 & - \\ & \text { Upper CI } & 0.63 & 0.61 & 0.55 & 0.48 & 0.24 & -\end{array}$




\section{Study 2}

The two factors had a poor initial model fit in CFA: $\chi^{2}=460.49(118), p<0.001, \mathrm{CFI}=0.85$, $\mathrm{TLI}=0.82, \mathrm{RMSEA}=0.11(\mathrm{CI}[0.10,0.12]), \mathrm{SRMR}=0.08, \mathrm{GFI}=0.80$. Modification indices and correlation and covariance matrices indicated several strongly-cross-loading and highlycovarying items. ${ }^{3}$

Table 6. Final scale items after iterative confirmatory factor analyses.

Final Epistemic Weather Curiosity Questionnaire Items After CFA

Number in parenthesis indicates factor

1. I would be interested in weather-related science experiments (e.g., creating a cloud in a bottle). (1)

2. I am curious about why the weather changes. (1)

3. I want to know what causes tornadoes. (1)

4. I would like to learn about high and low pressure systems. (1)

5. I like when meteorologists on TV talk about the science behind weather. (1)

6. It would be interesting to see a weather balloon launch. (1)

7. I like to watch TV news reports about weather. (2)

8. I feel drawn to learning about weather. (2)

9. Weather easily captures my attention. (2)

10. I like to search for answers to questions about weather. (2)

11. I have some interest in learning how to read computer weather models. (2)

Note. Factors are denoted in parentheses. Factor 1 assesses Curiosity for Weather Science; Factor 2 assesses a general, Information-driven Curiosity for Weather. Scale scores are the sum of the items.

\footnotetext{
${ }^{3}$ The strongest cross-loaders, with the following item number mentions referencing Table 4, were items 10 (with 11 and 12). We incrementally tested the effect of removal on model fit by first removing items 11 and 12, which were redundant and did not, in our opinion, enhance face validity over item 10 . The modification indices then revealed items 4 and 8 as high cross-loaders among the remaining items. Since item 8 was a much more specific manifestation of curiosity unlikely to be experienced by all but the most curious (and perhaps previously knowledgeable about weather), we opted to remove it. Covariance/correlational analyses at this point showed items 3 and 4,1 and 2, and 10 and 15 as the highest cross-loaders. To reduce redundancy and in the interest of item clarity and guided by theoretical parsimony, we decided to remove item 14. Finally, we removed items 2 and 4 due to their high correlations with items 1 and 3, respectively.
} 
An 11-item model (Table 6, Figure 3) yielded by a series of systematic, data-driven item reductions carried out on the 17 items was significantly improved over the initial fit, and had excellent psychometric properties: $\chi^{2}=56.92(43), p=0.076, \mathrm{CFI}=0.99, \mathrm{TLI}=0.99, \mathrm{RMSEA}=$ $0.038(\mathrm{CI}[0.000,0.06]), \mathrm{SRMR}=0.04, \mathrm{GFI}=0.96$.

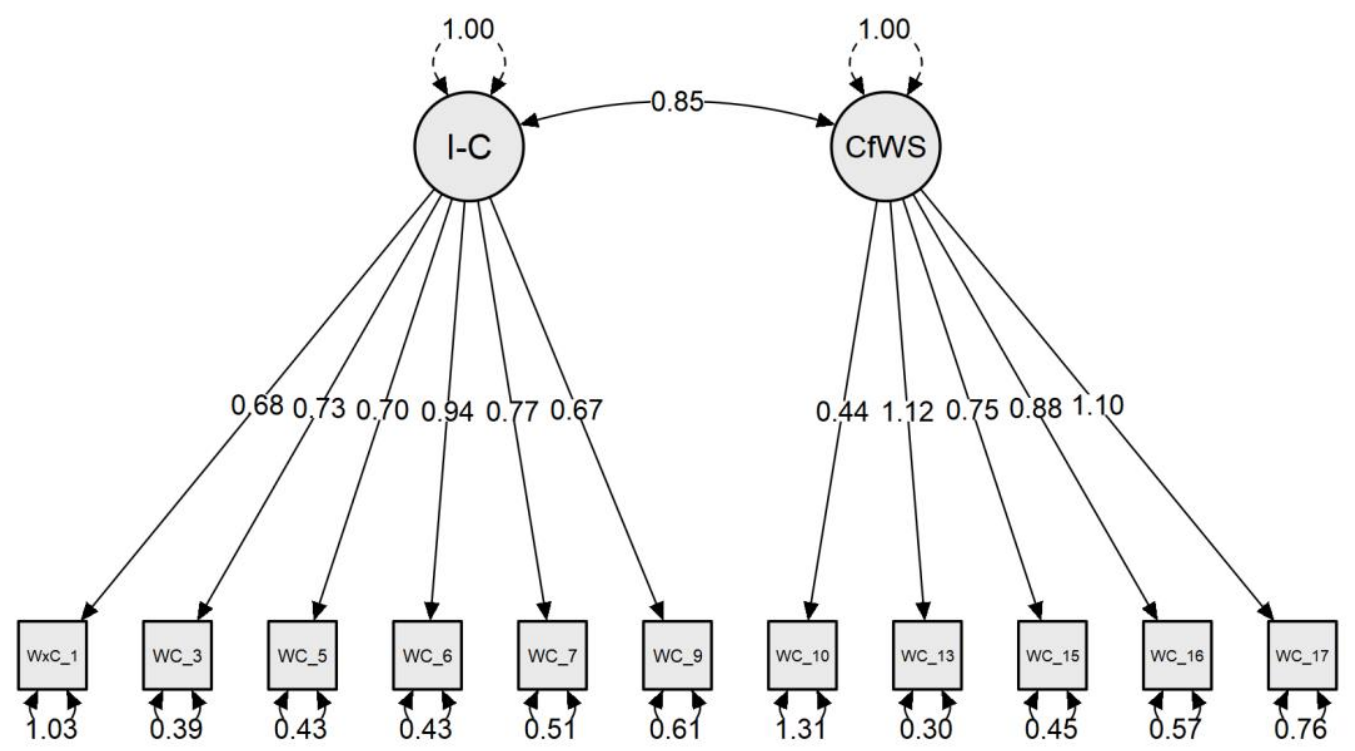

Figure 3. Confirmatory factor analysis model plot for 11-item EWCQ solution. 


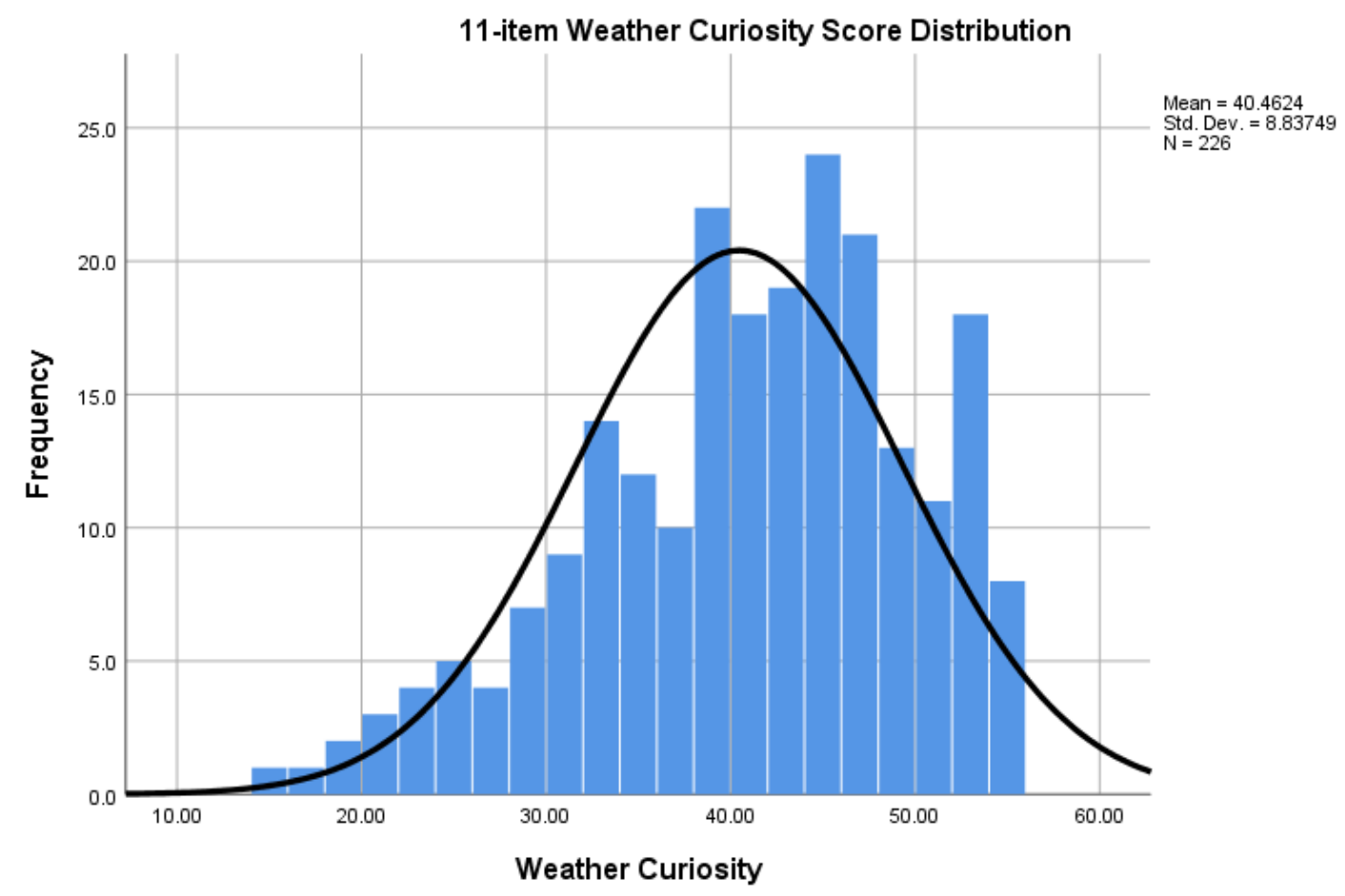

Figure 4. Distribution for the 2-factor, 11-item Epistemic Weather Curiosity Questionnaire derived through confirmatory factor analyses in study 2 .

These items also demonstrated strong reliability (Total $\alpha$ : 0.90; Factor 1: 0.88; Factor 2: 0.86).

The data again skewed left (Figure 4 above), suggesting most people are at least somewhat weather-curious in an epistemic sense. 
Pearson bivariate $r$ correlations showed the 11-item iteration of the EWCQ converged well with the accompanying measures

(Table 7). Notably, the SCILE, intended as a discriminant measure, positively correlated with EWC.

\begin{tabular}{|c|c|c|c|c|c|c|c|c|}
\hline Variable & & WxSQ & IC & $\mathrm{DC}$ & Openness & SCILE & SQ & EWCQ-11 \\
\hline \multirow[t]{5}{*}{ WxSQ } & $n$ & - & & & & & & \\
\hline & Pearson's $r$ & - & & & & & & \\
\hline & $p$-value & - & & & & & & \\
\hline & Upper CI & - & & & & & & \\
\hline & Lower CI & - & & & & & & \\
\hline \multirow[t]{5}{*}{ IC } & $n$ & 212 & - & & & & & \\
\hline & Pearson's $r$ & .28 & - & & & & & \\
\hline & $p$-value & $<0.001$ & - & & & & & \\
\hline & Lower CI & 0.15 & - & & & & & \\
\hline & Upper CI & 0.40 & - & & & & & \\
\hline \multirow[t]{5}{*}{$\mathrm{DC}$} & $n$ & 212 & 221 & - & & & & \\
\hline & Pearson's $r$ & .25 & .59 & - & & & & \\
\hline & $p$-value & $<0.001$ & $<0.001$ & - & & & & \\
\hline & Lower CI & 0.12 & 0.50 & - & & & & \\
\hline & Upper CI & 0.38 & 0.67 & & & & & \\
\hline \multirow[t]{2}{*}{ Openness } & $n$ & 208 & 215 & 215 & - & & & \\
\hline & Pearson's $r$ & .21 & .58 & .32 & - & & & \\
\hline
\end{tabular}




\begin{tabular}{|c|c|c|c|c|c|c|c|c|}
\hline & $p$-value & 0.003 & $<0.001$ & $<0.001$ & - & & & \\
\hline & Lower CI & 0.07 & 0.48 & 0.20 & - & & & \\
\hline & Upper CI & 0.33 & 0.66 & 0.44 & - & & & \\
\hline \multirow[t]{5}{*}{ SCILE } & $n$ & 205 & 209 & 209 & 208 & - & & \\
\hline & Pearson's $r$ & .25 & .67 & .49 & .56 & - & & \\
\hline & $p$-value & $<0.001$ & $<0.001$ & $<0.001$ & $<0.001$ & - & & \\
\hline & Lower CI & 0.11 & 0.59 & 0.38 & 0.46 & - & & \\
\hline & Upper CI & 0.37 & 0.74 & 0.59 & 0.65 & - & & \\
\hline \multirow[t]{5}{*}{ SQ } & $n$ & 190 & 194 & 194 & 193 & 195 & - & \\
\hline & Pearson's $r$ & .43 & .47 & .42 & .36 & .51 & - & \\
\hline & $p$-value & $<0.001$ & $<0.001$ & $<0.001$ & $<0.001$ & $<0.001$ & - & \\
\hline & Lower CI & 0.30 & 0.36 & 0.29 & 0.23 & 0.39 & - & \\
\hline & Upper CI & 0.53 & 0.58 & 0.53 & 0.48 & 0.60 & - & \\
\hline \multirow[t]{5}{*}{ EWCQ-11 } & $n$ & 211 & 219 & 219 & 213 & 207 & 192 & - \\
\hline & Pearson's $r$ & .60 & .38 & .31 & .22 & .33 & .64 & - \\
\hline & $p$-value & $<0.001$ & $<0.001$ & $<0.001$ & 0.001 & $<0.001$ & $<0.001$ & - \\
\hline & Lower CI & 0.51 & 0.26 & 0.19 & 0.09 & 0.20 & 0.54 & - \\
\hline & Upper CI & 0.68 & 0.49 & 0.43 & 0.34 & 0.45 & 0.71 & - \\
\hline
\end{tabular}

Note. Dunn-Bonferroni confidence intervals (CI) estimate the range in which the correlation could be expected to fall if the study were conducted multiple times with the same sample size drawn from the same population. 
The first linear regression showed that EWCQ score was a significant predictor of engagement with meteorological content and information $(\beta=0.17, p<0.001)$, accounting for $21 \%$ of the variance in our measure of weather-engaging behaviors. Thus, participants' predicted curiosity equaled $13.90+0.17$ weather engagement behaviors; that is, there was a 0.17-point increase in the number of engagement behaviors for every point-increase in curiosity. Confidence intervals for predicted curiosity were 12.09 and 15.71, and for weather engagement behaviors were 0.12 and 0.21 .

The second regression showed that imagining an inability to engage in EWC-driven thinking and information-gathering was significantly predictive of negative affect in the subset of the sample interested in weather $(\beta=0.31, p<0.001)$, accounting for $31 \%$ of the variance in negative emotionality. Predicted negative affect equaled $40.40+0.31$ negative emotions, indicating there was a 0.31 -point increase in negative affect for every point-increase in imagined lack of curiosity and information-gathering. Confidence intervals for predicted negative affect were 37.39 and 43.40, and for imagined lack of curiosity and information-gathering were 0.15 and 0.47 .

\section{Discussion}

This paper contributes to the psycho-meteorological literature by presenting the first validated self-report measure of EWC, the Epistemic Weather Curiosity Questionnaire (EWCQ). In two studies we validated, from an initial candidate pool of 23, 11 items which had excellent psychometric properties and fit to two factors measuring an information-driven curiosity for weather and curiosity for the science behind weather. 
The EWCQ demonstrated good convergent validity overall. It was significantly and positively correlated with measures of:

- weather salience and systemizing across both studies;

- weather warning awareness and beliefs about one's ability to prepare for severe weather in study 1 ; and

- $\quad$ EC (both I- and D-types) in study 2.

The results of our two studies suggest EWC is related to information-gathering behaviors during severe weather situations, beliefs about weather hazard preparedness, and EC more generally, as well as to an analytical cognitive style. Non-significant storm-safety behavior associations suggest the primarily learning/education-based construct captured by the EWCQ does not translate into protective action despite associations with protective action self-efficacy beliefs. The association between storm safety behaviors and weather warning awareness trended towards significance, however; this linkage makes sense and is one topic which further research could explore in larger sample sizes.

The EWCQ's association with both I- and D-type EC suggests people seek out weather information both because they are curious to learn more about and understand it conceptually and because they do not wish to be deficient in knowing what the weather is doing. Considering these elements of curiosity, the consistent left skew to the EWCQ data makes sense.

Although the SCILE was included as an indicator of discriminant validity, it too was positively correlated with the EWCQ. This was unanticipated but is actually unsurprising; it suggests EWC is just one sub-type in a larger set of science curiosities (Bolton et al., 2020; Feist, 2006; Zeyer, 2010, 2018; Zeyer \& Wolf, 2010). One interpretation is that various types of 
science curiosity may share common causal mechanisms (e.g., detail-orientation and pattern recognition induced by systemizing tendencies). The positive correlation between EWCQ score and systemizing tendency supports this reasoning. However, this result means the EWCQ's discriminant validity is still in question. Perhaps discriminant validity would best be demonstrated by less science-related individual differences (e.g., in trait nature connectedness).

Finally, using a composite measure of different activities, EWCQ score was positively associated with active engagement with weather information, demonstrating predictive validity. Questionnaire score was also associated with higher negative affect for the subset of weatherinterested participants induced to imagine they could no longer engage with weather information. This finding is consistent with research linking subjective wellbeing with the ability to pursue personal interests and meaningful and engaging endeavors (Grove et al., 2018; Schueller \& Seligman, 2010; Vella-Brodrick et al., 2009).

\section{Conclusions, Limitations, and Future Work}

This study presents the first validated epistemic weather curiosity measure. The scalefeaturing excellent psychometric qualities including convergent validity with measures of weather salience, weather warning awareness, and epistemic and scientific curiosity-consists of 11 items assessing informational curiosity for weather on two factors related to general weather interest and curiosity for learning the science behind weather.

However, these studies are not without limitations. Self-report always involves concerns including item understanding and participant honesty; and further psychometric replication and testing (including test-retest reliability and discriminant validity) is needed before we can most confidently infer results and the scale's stability. One concern that occurred to us late in this 
project is that one item initially included deals with "reading" rather than "interpreting" computer weather models. This may cause subtle functioning differences in responses by different groups, given lay-people likely would not "read" a weather model as might a meteorologist or weather enthusiast. A future change in the item's wording item may produce better psychometrics and strengthen the scale's validity through its re-introduction to the EWCQ.

These concerns notwithstanding, the EWCQ is a promising measurement tool. It could be helpful to meteorologists participating in outreach activities, allowing EWC-quantification in weather-interested individuals with whom they interact. Further, given its brevity and straightforwardness of administration (simply sum the items to produce a total score), educators and researchers could quickly assess EWC in classroom or other settings, including in the context of curriculum assessment. With respect to future work, the scale could be expanded; possible investigation of cut-points to establish quantified levels of EWC and the inclusion of other possible EWC item factors would be useful to those interested in measuring EWC individual differences. Finally, nature-connectedness is a candidate discriminate construct, as there is overlap but less scientific emphasis between nature and weather interest.

\section{Acknowledgements}

MJB conceived the project. MJB, DRA, and HMM formulated the EWCQ items. MJB, LKA, and KB analyzed the data. MJB, the primary manuscript author with support from LKA, $\mathrm{KB}$, and DRA, was supported academically during the period of this work by a Graduate Fellowship sponsored by the U.S. National Weather Service and awarded by the American Meteorological Society. The opinions, conclusions, and recommendations expressed here are 
those of the authors and do not necessarily reflect the views of the National Weather Service or American Meteorological Society. We have no conflicts of interest to declare. 


\section{Appendix A}

\section{Weather Engagement Items Used in Regression}

How likely would you be to do each of the following?

a. Mention to a friend in conversation how nice or bad the current weather conditions are.

b. Share weather information with a friend or family member.

c. Post about weather on social media.

d. Take photos of clouds or other atmospheric phenomena.

e. Check the weather forecast at least three times per week. 


\section{References}

Allan, J. N., Ripberger, J. T., Ybarra, V. T., \& Cokely, E. T. (2017). The Oklahoma Warning Awareness Scale: A psychometric analysis of a brief self-report survey instrument. Proceedings of the Human Factors and Ergonomics Society Annual Meeting, 61(1), 1203-12007. https://doi.org/10.1177/1541931213601783

Bjerknes, V. (1921). On the dynamics of the circular vortex: With applications to the atmosphere and atmospheric vortex and wave motions. Geofysiske Publikationer, 2(4).

Baron-Cohen, S. (2006). The hyper-systemizing, assortative mating theory of autism. Progress in Neuropsychopharmacology and Biological Psychiatry, 30, 865-872, https://doi.org/10.1016/j.pnpbp.2006.01.010

Baron-Cohen, S. (2020). The pattern-seekers: How autism drives human invention. Basic Books.

Bolton, M. J., Blumberg, W. G., Ault, L. K., Mogil, H. M., \& Hanes, S. H. (2020). Initial evidence for increased weather salience in autism spectrum conditions. Weather, Climate, and Society, 12(2), 293-307. https://doi.org/10.1175/WCAS-D-18-0100.1

Bolton, M. J., Mogil, H. M., \& Ault, L. K. (2020). An exploratory, preliminary report on United States weather education trends and general population links between weather salience and systemizing. Journal of Operational Meteorology, 8(4), 54-63. https://doi.org/10.15191/nwajom.2020.0804

De Figueiredo Neves, G. Z., Gallardo, N. P., \& da Silva Vecchia, F. A. (2017). A short critical history on the development of meteorology and climatology. Climate, 5(23). https://doi.org/10.3390/cli5010023 
Evans, G. W., \& Cohen, S. (1987). Environmental stress. In D. Stokols \& I. Altman, (Eds.), Handbook of environmental psychology. John Wiley.

Evans, G. W., \& Stecker, R. (2004). Motivational consequences of environmental stress. Journal of Environmental Psychology, 24, 143-165. https://doi.org/10.1016/S0272$\underline{4944(03) 00076-8}$

Feist, G. J. (2006). The psychology of science and the origins of the scientific mind. Yale University Press.

Field, A. (2013). Discovering statistics using SPSS, 4th edition. SAGE.

Gardner, P. L. (1987). Comments on “toward the development of a children's science curiosity scale.” Journal of Research in Science Teaching, 24(2), 175-176. https://doi.org/10.1002/tea.3660240209

Greenberg, D. M., Warrier, V., Allison, C., \& Baron-Cohen, S. (2018). Testing the EmpathizingSystemizing theory of sex differences and the Extreme Male Brain theory of autism in half a million people. Proceedings of the National Academies of Science, 115(48), 12152-12157. https://doi.org/10.1073/pnas.1811032115

Grove, R., Hoekstra, R. A., Wierda, M., \& Begeer, S. (2018). Special interests and subjective wellbeing in autistic adults. Autism Research, 11, 766-775. https://doi.org/10.1002/aur.1931

Harty, H., \& Beall, D. (1984). Toward the development of a children's science curiosity measure. Journal of Research in Science Teaching, 21(4), 425-436. https://doi.org/10.1002/tea.3660210410 
Helmholtz, H. (1858). Über Integrale der hydrodynamischen Gleichungen, welche den Wirbelbewegungen entsprechen. Journal für die reine und angewandte Mathematik, 55, $25-55$.

Howard, L. (1803). On the modification of clouds. John Churchill and Sons.

Jankovic, V. (2006). The end of classical meteorology, c. 1800. In G. J. H. McCall, A. J. Bowden, \& R. J. Howarth, (Eds.), The history of meteoritics and key meteorite collections: Fireballs, falls and finds (pp. 91-99). Geological Society of London.

Kanyongo, G. Y. (2005). Determining the correct number of components to extract from a principal components analysis: A Monte Carlo study of the accuracy of the scree plot. Journal of Modern Applied Statistical Methods, 4, 120-133. https://doi.org/10.22237/jmasm/1114906380

Kline, R. B. (1998) Principles and practices of structural equation modeling. Guilford Press.

Kozhevnikov, M. (2007). Cognitive styles in the context of modern psychology: Toward an integrated framework of cognitive style. Psychological Bulletin, 133(3), 464481. https://doi.org/10.1037/0033-2909.133.3.464

Krause, K. L., MacDonald, E. M., Goodwill, A. M., Vorstenbosch, V., \& Antony, M. M. (2017). Assessing safety behaviors in fear of storms: Validation of the Storm-related Safety Behavior Scale. Journal of Psychopathology and Behavior Assessment, 40, 139-148. https://doi.org/10.1007/s10862-017-9622-x

Litman, J. A. (2008). Interest and deprivation dimensions of epistemic curiosity. Personality and Individual Differences, 44, 1585-1595. https://doi.org/10.1016/j.paid.2008.01.014 
Litman, J. A., \& Spielberger, C. D. (2003). Measuring epistemic curiosity and its diversive and specific components. Journal of Personality Assessment, 80, 75-86. https://doi.org/10.1207/S15327752JPA8001_16

Litman, J. A., \& Jimerson, T. L. (2004) The measurement of curiosity as a feeling-ofdeprivation. Journal of Personality Assessment, 82, 147-157. https://doi.org/10.1207/s15327752jpa8202_3

Ludlum, D. (1984). The weather factor. Springer.

Maddern, C., \& Jenner, D. (2009). Public user survey - summer 2009. A report of research findings. Australian Bureau of Meteorology. https://www.wmo.int/pages/prog/amp/pwsp/documents/Public_User_Survey_Report_Su $\underline{\text { mmer09_Australia.pdf }}$

McCrae, R. R., \& Costa, P. T. (2008). The Five-Factor Theory of personality. In O. P. John, R. W. Robins, \& L. A. Pervin (Eds.), Handbook of personality: Theory and research (3rd ed., pp. 159 -181). Guilford Press.

Meleshko, V. V., \& Aref, H. (2007). A bibliography of vortex dynamics 1858-1956. In E. van Giessen \& H. Aref, (Eds.), Advances in applied mechanics. Elsevier.

Osborne, J. W. (2015). What is rotating in exploratory factor analysis? Practical Assessment, Research, and Evaluation. 20(2). https://doi.org/10.7275/hb2g-m060

Phan, M. D., Montz, B. E., Curtis, S., \& Rickenbach, T. M. (2018). Weather on the go: An assessment of smartphone mobile weather application use among college students. Bulletin of the American Meteorological Society, 99, 2245-2257. https://doi.org/10.1175/BAMS-D-18-0020.1 
Rogers, C. R. (1954). Toward a theory of creativity. Etc., 11, 249-260.

Schueller, S. M., \& Seligman, M. E. P. (2010). Pursuit of pleasure, engagement, and meaning: Relationships to subjective and objective measures of well-being. Journal of Positive Psychology, 5(4), 253-263. https://doi.org/10.1080/17439761003794130

Seargent, D. A. J. (2012). Weird weather: Tales of astronomical and atmospheric anomalies. Springer.

Sneed, C. D., McCrae, R. R., \& Funder, D. C. (1998). Lay conceptions of the Five-Factor Model and its indicators. Personality and Social Psychology Bulletin, 24(2), 115-126. https://doi.org/10.11770146167298242001

Stewart, A. E. (2009). Minding the weather: The measurement of weather salience. Bulletin of the American Meteorological Society, 90(12), 1833-1842. https://doi.org/10.1175/2009bams2794.1

Stewart, A. E. (2015). The measurement of personal self-efficacy in preparing for a hurricane and its role in modeling the likelihood of evacuation. Journal of Marine Science and Engineering, 3, 630-653.https://doi.org/10.3390/jmse3030630

Stewart, A. E. (2017, December). Assessing weather curiosity in university students. Presentation at the Annual Meeting of the American Geophysical Union, San Francisco, CA.

Stewart, A. E., Lazo, J. K., Morss, R. E., \& Demuth, J. L. (2012). The relationship of weather salience with the perceptions and uses of weather information in a nationwide sample of the United States. Weather, Climate, and Society, 4(3), 172-189. https://doi.org/10.1175/wcas-d-11-00033.1 
Stewart, A. E., Knox, J. A., \& Schneider, P. (2015). Piloting and evaluating a workshop to teach Georgia teachers about weather science and safety. Journal of Geoscience Education, 63(4), 271-284. https://doi.org/10.5408/14-069.1

Stewart, A. E., Knox, J. A., \& Schneider, P. (2018). Reaching students and parents through weather science and safety workshops for teachers. Bulletin of the American Meteorological Society, 99(8), 1545-1555. https://journals.ametsoc.org/doi/10.1175/BAMS-D-17-0114.1

Stokols, D. (1979). A congruence analysis of human stress. In I. G. Sarason \& C. D. Spielberger, (Eds.), Stress and Anxiety, Vol. 6. Hemisphere (pp. 27-53).

Stokols, D. (1995). The paradox of environmental psychology. American Psychologist, 50(10), $821-837$.

Strauss, S., \& Orlove, B. S. (2003). Weather, climate, culture. Berg Publishers.

Soto, C. J., \& John, O. P. (2017). The next Big Five Inventory (BFI-2): Developing and assessing a hierarchical model with 15 facets to enhance bandwidth, fidelity, and predictive power. Journal of Personality and Social Psychology, 113, 117-143. https://doi.org/10.1037/pspp0000096

Tabachnick, B. G., \& Fidell, L. S. (2014). Using multivariate statistics, 6th edition. Pearson.

Tullett, A. M., Kay, A. C., \& Inzlicht, M. (2015). Randomness increases self-reported anxiety and neurophysiological correlates of performance monitoring. Social Cognitive and Affective Neuroscience, 10(5), 628-635. https://doi.org/10.1093/scan/nsu097 
U.K. Met Office. (2015, August 14). Met Office releases new research looking at the U.K.'s obsession with the weather. https://web.archive.org/web/20171113060023/https://www.metoffice.gov.uk/news/releas es/2015/weather-research-wow

Vella-Brodrick, D. A., Park, N., \& Peterson, C. (2009). Three ways to be happy: Pleasure, engagement, and meaning-findings from Australian and US samples. Social Indicators Research, 90, 165-179. https://doi.org/10.1007/s11205-008-9251-6

Watkins, M. W. (2018). Exploratory factor analysis: A guide to best practice. Journal of Black Psychology, 44(3), 219-246. https://doi.org/10.1177/0095798418771807

Watson, D., Clark, L. A., \& Tellegen, A. (1988). Development and validation of brief measures of positive and negative affect: The PANAS scales. Journal of Personality and Social Psychology, 54(6), 1063-1070. https://doi.org/10.1037/0022-3514.54.6.1063

Weible, J. L., \& Zimmerman, H. T. (2016). Science curiosity in learning environments: Developing an attitudinal scale for research in schools, homes, museums, and the community. International Journal of Science. Education, 38, 1235-1255. https://doi.org/10.1080/09500693.2016.1186853

Williams, C. A., Miller, P. A., Black, A. W., \& Knox, J. A. (2017). Throwing caution to the wind: National Weather Service wind products as perceived by a weather-salient sample. Journal of Operational Meteorology, 5(9), 103-120. https://doi.org/10.15191/nwajom.2017.0509

Wright, D., \& Skagerberg, E. M. (2012). Measuring empathizing and systemizing with a large US sample. PLoS ONE, 7(2), e31661. https://doi.org/10.1371/journal.pone.0031661 
Yuhas, D. (2012, July 18). Storm scents: It's true, you can smell oncoming summer rain. Scientific American. https://www.scientificamerican.com/article/storm-scents-smell-rain/

Zeyer, A. (2010). Motivation to learn science and cognitive style. EURASIA Journal of Mathematics, Science, and Technology Education, 6(2), 123-130. https://doi.org/10.12973/ejmste/75233

Zeyer, A. (2018). Gender, complexity, and science for all: Systemizing and its impact on motivation to learn science for different science subjects. Journal of Research in Science Teaching, 55(2), 147-171. https://doi.org/10.1002/tea.21413

Zeyer, A., \& Wolf, S. (2010). Is there a relationship between brain type, sex, and motivation to learn science? International Journal of Science Education, 32(16), 2217-2233. https://doi.org/10.1080/09500690903585184 